\title{
Correction to: Accurate Ocean Bottom Seismometer Positioning Method Inspired by Multilateration Technique
}

\author{
Omar Benazzouz ${ }^{1}$ • Luis M. Pinheiro' ${ }^{1}$ - Luis M. A. Matias ${ }^{2}$. \\ Alexandra Afilhado ${ }^{3}$. Daniel Herold ${ }^{4}$. Seth S. Haines ${ }^{5}$
}

Published online: 1 February 2018

(C) International Association for Mathematical Geosciences 2018

\section{Correction to: Math Geosci https://doi.org/10.1007/s11004-017-9719-5}

The original version of this article unfortunately contained a mistake. The "Acknowledgments" were uncomplete. The missing sentence is: Thanks are due, for the financial support, to CESAM (UID/AMB/50017-POCI-01-0145-FEDER-007638) and to FCT/MCTES through national funds (PIDDAC), and, for the co-funding, to the FEDER, within the PT2020 Partnership Agreement and Compete 2020.

The original article can be found online at https://doi.org/10.1007/s11004-017-9719-5.

Omar Benazzouz

gibnem@gmail.com

1 Department of Geosciences, University of Aveiro, Aveiro, Portugal

2 Instituto Dom Luiz, Faculdade de Ciências, Universidade de Lisboa, Lisbon, Portugal

3 Instituto Superior de Engenharia de Lisboa, Instituto Politecnico de Lisboa, Lisbon, Portugal

4 Parallel Geoscience Corporation, Crystal Bay, NV, USA

5 Central Energy Resources Science Center, United States Geological Survey, Denver, CO, USA 